\title{
Tibial Tubercle Osteotomy in Patello-Femoral Instability: Results of a Series of 12 Cases Treated by the Elmslie-Trillat Procedure with Literature Review
}

\author{
Hatim Abid*, Mohammed El Idrissi, Abdelhalim El Ibrahimi, Abdelmajid Elmrini \\ Department of Osteoarticular Surgery B4, HASSAN II Teaching Hospital, Fes, Morocco \\ Email: ^hatim.abid1@gmail.com
}

How to cite this paper: Abid, H., El Idrissi, M., El Ibrahimi, A. and Elmrini, A. (2020) Tibial Tubercle Osteotomy in Patello-Femoral Instability: Results of a Series of 12 Cases Treated by the Elmslie-Trillat Procedure with Literature Review. Open Access Library Journal, 7: e6593.

https://doi.org/10.4236/oalib.1106593

Received: July 8, 2020

Accepted: September 26, 2020

Published: September 29, 2020

Copyright $\odot 2020$ by author(s) and Open Access Library Inc.

This work is licensed under the Creative Commons Attribution International License (CC BY 4.0).

http://creativecommons.org/licenses/by/4.0/

\begin{abstract}
Patellofemoral pain (PFP) in the context of patellar instability is a frequent and often challenging clinical problem that affects a young and active population: females more than males. Diagnosis of the specific cause requires a rigorous clinical and paraclinical conduct. The treatment for PFP is first of all conservative on the basis of specific physical therapy program. In case of failure of the latter, surgical treatment which can be categorized on soft tissue techniques and bone procedures, may be indicated. Surgical management of patellar instability should be personalized for obtaining good outcomes and avoiding early failure. We report a retrospective series of 12 cases of PFP treated by a tibial tubercle osteotomy with a review of the literature.
\end{abstract}

\section{Subject Areas}

Surgery \& Surgical Specialties

\section{Keywords}

Patellofemoral Pain, Patellar Instability, Tibial Tubercle Osteotomy

\section{Introduction}

Patellofemoral pain (PFP) is a common and challenging problem in active patients and may account for $25 \%$ to $40 \%$ of all knee problems [1]. PFP is more common in women and includes a wide spectrum of conditions corresponding to patellofemoral dysfunction, extensor mechanism malalignment, patellofemoral dysplasia, chondromalacia, and arthritis [2]. Regarding therapeutic man- 
agement, if conservative treatment is unsuccessful, several surgical techniques have been described. The choice of the most appropriate surgical technique depends on many factors including the general state of patients, their age and activity level. The transfer of the tibial tubercle is an effective treatment option for PFP in young patients [3] [4]. We share through this article our experience concerning the management of PFP in the context of patellar instability and lateral maltracking by a tibial tubercle osteotomy performed in 12 young and active patients.

\section{Patients and Method}

12 patients with PFP were treated with tibial tubercle osteotomy during the last 3 years between January 2017 and December 2019. Inclusion criteria were PFP in the context of patellar instability that was resistant to muscular training program supervised by a physiotherapist, in young patients under 50 years treated by medialization osteotomy with or without combined lateral release, for minimum 1 year follow-up. We excluded knees with previous surgeries or inflammatory pathology, those treated by another type of osteotomy and combined procedures other than lateral release. 10 patients were women and 2 were men, their ages ranged from 28 to 44 years (mean 34). The patients were evaluated by several scores. The Lysholm functional score [5] which corresponds to a patient completed questionnaire includes 8 items that are limp, support, locking, instability, pain, swelling, stair climbing and squatting. The eight factors are rated to produce an overall score on a point scale of 0 to 100 (Table 1). The Tegner activity score [6] which is a graduated list of activities of daily living, recreation and competitive sports. It describes their current level of activity and that before injury with a score variation ranging from 0 to 10 (Table 2). The Beighton score [7] for overall joint laxity: this is a nine point scale and requires the performance of 5 maneuvers. A score of 4 or more out of 9 indicates generalized hypermobility of the joints (Table 3 ). We searched patellofemoral crepitus, quadriceps muscle atrophy, femoral anteversion [8] and foot pronation. We measured knee range of motion and Q angle [9]. All patients underwent radiological assessment including standard anteroposterior, true lateral, and $30^{\circ}$ Merchant views of both knees. In addition Magnetic resonance imaging (MRI) of the affected knee was performed to exclude associated soft tissue injuries. A Computerized tomography (CT-scan) was performed to assess especially the tibial tubercle-trochlear groove (TT-TG) distance (Figure 1).

In our study, to calculate the height of the patella, we used Insall-Salvati ratio [10]. The patella was considered Alta with an Insall-Salvati ratio greater than 1.5, infra with a ratio less than 0.75 , and normal with a ratio between 0.75 and 1.5 [10] [11]. The shape of the patella was classified according to the Wiberg classification [12]. All patients have had surgery using a medialization osteotomy (Figure 2), by an anterior incision of 6 to $8 \mathrm{~cm}$ slightly lateral to the tibial tuberosity, fixed with two $4.5 \mathrm{~mm} \mathrm{AO}$ screws. The patellofemoral tracking was reas- 
sessed and if necessary, lateral release and vastus Medialis Obliquus Advancement were added. Postoperatively, the operated knee benefited from control $\mathrm{X}$-rays (Figure 3 ) and was placed in a knee brace. All patients started immediate range of motion and used crutches for 6 weeks.

Table 1. Lysholm scoring scale.

\begin{tabular}{|c|c|c|}
\hline \multicolumn{3}{|c|}{ Lysholm Knee Scoring Scale } \\
\hline Factor & Scale & Points \\
\hline \multirow[t]{3}{*}{ Limb } & None & 5 \\
\hline & Slight or periodic & 3 \\
\hline & Severe and constant & 0 \\
\hline \multirow[t]{3}{*}{ Support } & None & 5 \\
\hline & Stick or crutch & 2 \\
\hline & Weight-bearing impossible & 0 \\
\hline \multirow[t]{5}{*}{ Locking } & No locking/catching sensations & 15 \\
\hline & Catching sensation but no locking & 10 \\
\hline & Locking: occasionally & 6 \\
\hline & Locking: frequently & 2 \\
\hline & Locked joint on examination & 0 \\
\hline \multirow[t]{6}{*}{ Instability } & Never giving-way & 25 \\
\hline & Rarely during athletics or other severe exertion & 20 \\
\hline & $\begin{array}{l}\text { Frequently during athletics or other severe exertion } \\
\text { (or incapable of participation) }\end{array}$ & 15 \\
\hline & Occasionally in daily activities & 10 \\
\hline & Often in daily activities & 5 \\
\hline & Every step & 0 \\
\hline \multirow[t]{6}{*}{ Pain } & None & 25 \\
\hline & Inconstant and slight during severe exertion & 20 \\
\hline & Marked during severe exertion & 15 \\
\hline & Marked on or after walking $>2 \mathrm{~km}$ & 10 \\
\hline & Marked on or after walking $<2 \mathrm{~km}$ & 5 \\
\hline & Constant & 0 \\
\hline \multirow[t]{4}{*}{ Swelling } & None & 10 \\
\hline & On severe exertion & 6 \\
\hline & On ordinary exertion & 2 \\
\hline & Constant & 0 \\
\hline \multirow[t]{4}{*}{ Stair-climbing } & No problems & 10 \\
\hline & Slightly impaired & 6 \\
\hline & One step at a time & 2 \\
\hline & Impossible & 0 \\
\hline \multirow[t]{4}{*}{ Squatting } & No problems & 5 \\
\hline & Slightly impaired & 4 \\
\hline & Not beyond 90 degrees & 2 \\
\hline & Impossible & 0 \\
\hline
\end{tabular}


Table 2. Tegner activity scale.

\section{TEGNER ACTIVITY LEVEL SCALE}

Please indicate in the spaces below the HIGHEST level of activity that you participated in before your injury and the highest level you are able to participate in currently.

BEFORE INJURY: Level

CURRENT: Level

- Level 10: Competitive sports-soccer, football, rugby (national elite)

- Level 9: Competitive sports-soccer, football, rugby (lower divisions), ice hockey, wrestling, gymnastics, basketball

- Level 8: Competitive sports-racquetball or bandy, squash or badminton, track and field athletics (jumping, etc.), down-hill skiing

- Level 7: Competitive sports-tennis, running, motorcars speedway, handball, Recreational sports-soccer, football, rugby, bandy, ice hockey, basketball, squash, racquetball, running

- Level 6: Recreational sports-tennis and badminton, handball, racquetball, down-hill skiing, jogging at least 5 times per week

- Level 5: Work-heavy labor (construction, etc.) Competitive sports-cycling, cross-country skiing, Recreational sports-jogging on uneven ground at least twice weekly

- Level 4: Work-moderately heavy labor (e.g. truck driving, etc.)

- Level 3: Work-light labor (nursing, etc.)

- Level 2: Work-light labor Walking on uneven ground possible, but impossible to back pack or hike

- Level 1: Work-sedentary (secretarial, etc.)

- Level 0: Sick leave or disability pension because of knee problems

Table 3. The Beighton scale.

\begin{tabular}{lcc}
\hline & LEFT & RIGHT \\
\hline $\begin{array}{l}\text { 1. Passive dorsiflexion and hyperextension of the fifth MCP joint beyond } 90^{\circ} \\
\text { 2. Passive apposition of the thumb to the flexor aspect of the forearm }\end{array}$ & 1 & 1 \\
$\begin{array}{l}\text { 3. Passive hyperextension of the elbow beyond } 10^{\circ} \\
\text { 4. Passive hyperextension of the knee beyond } 10^{\circ}\end{array}$ & 1 & 1 \\
$\begin{array}{l}\text { 5. Active forward flexion of the trunk with the knees fully extended so that the } \\
\text { palms of the hands rest flat on the floor }\end{array}$ & 1 \\
\multicolumn{1}{c}{ TOTAL } & 19
\end{tabular}

\section{Results}

The mean follow-up was 19 months (range 12 - 32 months), and the mean age at the time of surgery was 34 years. The alignment was varus in 3 of 12 knees (25\%), neutral in 3 cases (25\%), and valgus in 6 of 12 knees (50\%). The foot was pronated in 5 of 12 knees (42\%) and normally aligned in the rest of the series. According to Staheli et al. [8], increased femoral anteversion was noted in 3 of 12 knees (25\%) and was normal in the rest of the knees. The mean preoperative sulcus angle was $141.6^{\circ}$. The mean preoperative congruence angle was $13.2^{\circ}$. The mean preoperative patellar tilt angle was $10.5^{\circ}$ and the mean preoperative TT-TG distance was $16.2 \mathrm{~mm}$. Preoperatively, the patella was normal in 8 knees 


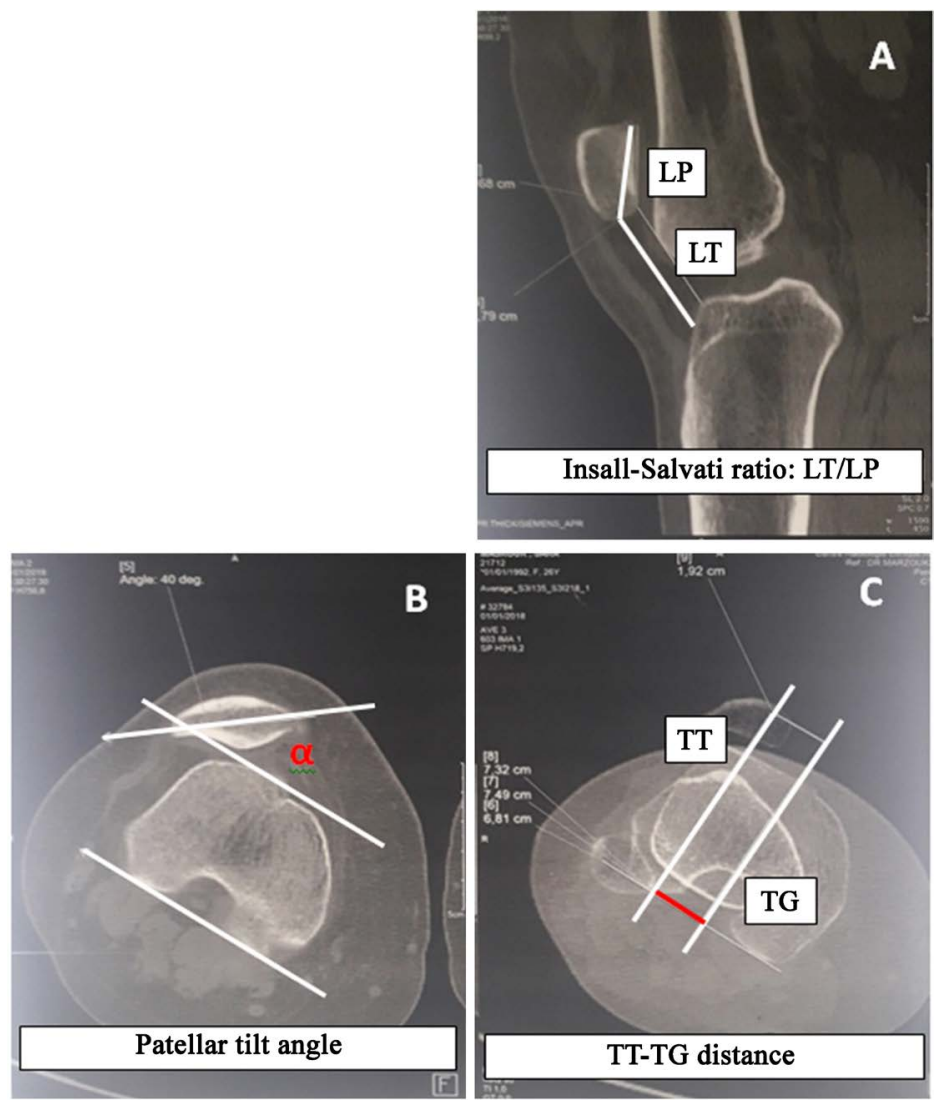

Figure 1. The measuring methods in computed tomography. (A) Insall-Salvati ratio calculated as a ratio of patellar tendon length (LT)/patella length (LP); (B) Patellar tilt angle a defined between transverse plane of patella and the line paralled to the tangential line of femoral posterior condyles; (C) TT-TG distance (tibial tuberosity-trochlear groove)

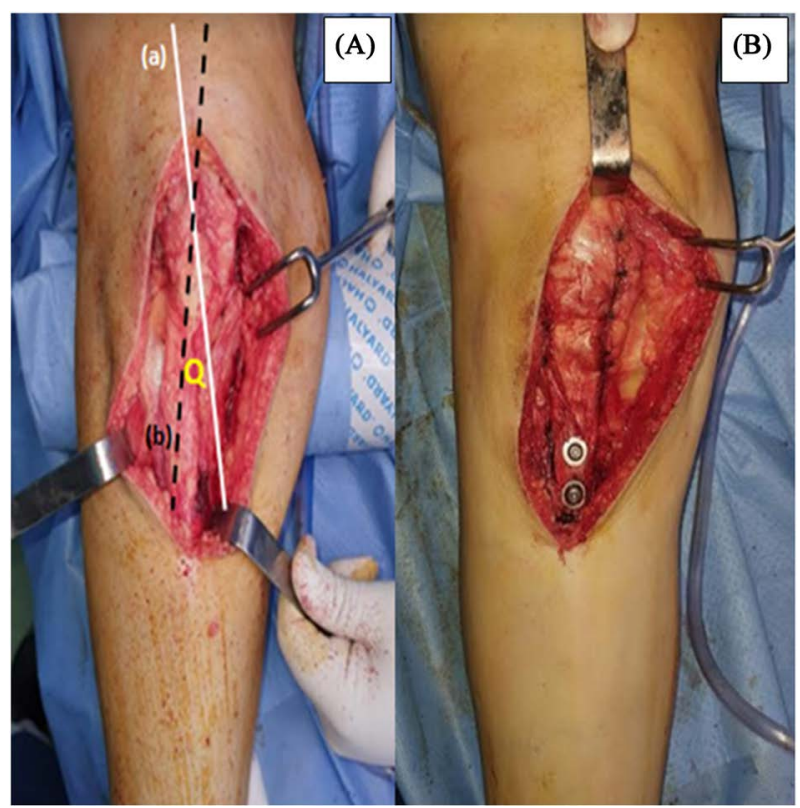

Figure 2. Intraoperative view of (A) the $\mathrm{Q}$ angle between the axis of the extensor mechanism (a) and the axis of the patellar tendon (b), (B) the tibial tubercle osteotomy, lateral release and vastus Medialis Obliquus Advancement. 
(66\%), and Alta in 4 cases (33\%). According to the Wiberg classification [12], the patella was type I in 4 of 12 knees (33\%) and type II in 8 cases (66\%) (Table 4).

The mean postoperative congruence angle and patellar tilt angle were $9.0^{\circ}$ and $5.9^{\circ}$ respectively. The patella was Alta in 2 knees (16\%), and normal in 10 knees (83\%). The mean preoperative Lysholm and Tegner scores were 55 and 4.6 points, respectively. After surgery our scores were improved; we report an average of 88 and 6.2 points for Lysholm and Tegner scores respectively (Table 5). Considering early complications, deep venous thrombosis was diagnosed in 1 knee (8\%). Postoperative stiffness was recorded in 1 knee $(8 \%)$ treated conservatively

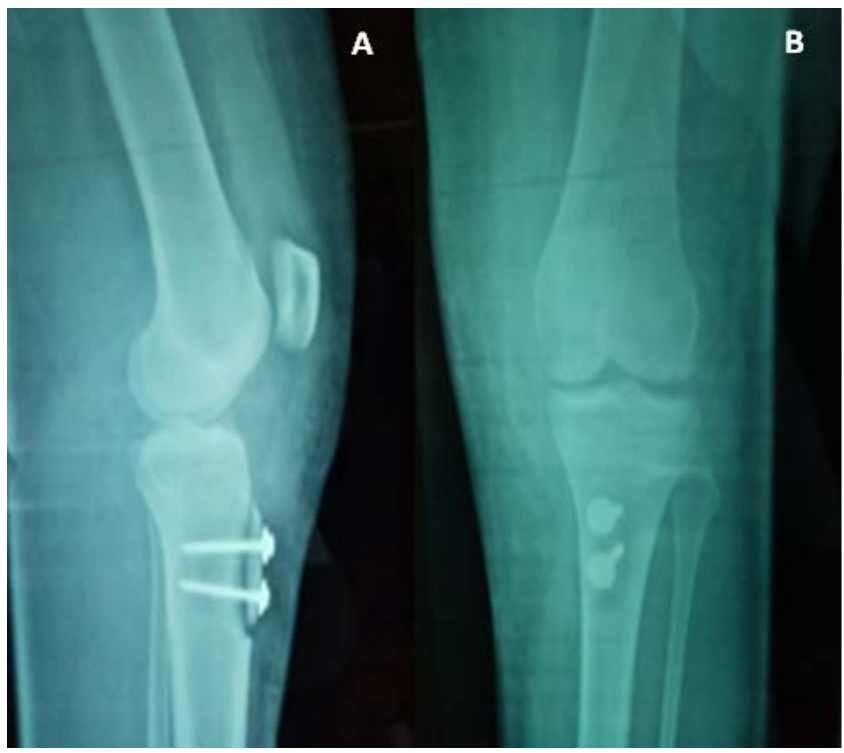

Figure 3. Postoperative (A) lateral and (B) anteroposterior radiographs of tibial tubercle osteotomy.

Table 4. Preoperative, postoperative, and follow-up data on 12 patients with tibial tubercle osteotomy.

\begin{tabular}{|c|c|c|c|c|c|c|c|c|}
\hline Patients & Sex & $\begin{array}{l}\text { Age at } \\
\text { surgery }\end{array}$ & $\begin{array}{l}\text { Follow up } \\
\text { by months }\end{array}$ & $\begin{array}{l}\text { Degree of chondromalacia } \\
\text { Outerbridge classification }\end{array}$ & $\begin{array}{c}\text { Facet involvement } \\
\text { Wiberg classification }\end{array}$ & $\begin{array}{l}\text { Self-assessment pain } \\
\text { and level of activity }\end{array}$ & $\begin{array}{l}\text { Unsatisfactory } \\
\text { scar }\end{array}$ & $\begin{array}{l}\text { Ability to } \\
\text { work }\end{array}$ \\
\hline 1 & $\mathrm{H}$ & 40 & 30 & Grade 2 & Type 2 & Improved & No & Yes \\
\hline 2 & $\mathrm{~F}$ & 28 & 18 & Grade 1 & Type 2 & Improved & No & Yes \\
\hline 3 & $\mathrm{~F}$ & 30 & 12 & Grade 2 & Type 1 & Unchanged & No & Yes \\
\hline 4 & $\mathrm{~F}$ & 32 & 15 & Grade 2 & Type 2 & Improved & No & Yes \\
\hline 5 & $\mathrm{~F}$ & 30 & 26 & Grade 2 & Type 1 & Improved & No & Yes \\
\hline 6 & $\mathrm{~F}$ & 35 & 20 & Grade 3 & Type 2 & Wrose & No & No \\
\hline 7 & $\mathrm{~F}$ & 42 & 14 & Grade 2 & Type 2 & unchanged & No & No \\
\hline 8 & $\mathrm{H}$ & 44 & 20 & Grade 1 & Type 1 & Improved & No & Yes \\
\hline 9 & $\mathrm{~F}$ & 36 & 16 & Grade 1 & Type 2 & Unchanged & No & Yes \\
\hline 10 & $\mathrm{~F}$ & 28 & 6 & Grade 2 & Type 2 & Improved & Yes & Yes \\
\hline 11 & $\mathrm{~F}$ & 30 & 32 & Grade 1 & Type 2 & Improved & No & Yes \\
\hline 12 & $\mathrm{~F}$ & 37 & 28 & Grade 1 & Type 1 & Improved & Yes & Yes \\
\hline
\end{tabular}


Table 5. Mean knee function before and after surgery for PFP in 12 patients.

\begin{tabular}{cccc}
\hline \multicolumn{2}{c}{ Lysholm score (mean) } & \multicolumn{2}{c}{ Tegner score (mean) } \\
\hline Pre op & Follow up & Pre op & Follow up \\
\hline 55 & 88 & 4.6 & 6.2 \\
\hline
\end{tabular}

with aggressive physical therapy. The most common delayed complication was discomfort related to the hardware. For this, 3 knees (25\%) required screw removal.

\section{Discussion}

The treatment of PFP in the context of patellar instability and lateral maltracking is a challenge for the orthopaedic surgeon mostly in those cases resistant to physical therapy. When non-operative treatment fails, different surgical procedures can be considered, which are categorized as soft tissue procedures (lateral release, medial imbrication, and MPFL repair or reconstruction) and bony procedures (tibial tubercle transfer procedures and trochleoplasty). Within this second category, tibial tubercle osteotomy is the most practiced technique and can be performed alone or combined with other procedures [13] [14] [15].

Technically we distinguish the anteriorization osteotomy first described in 1963 by Maquet to decrease load in a painful patellofemoral joint particularly in the case of mild to moderate patellofemoral arthritis [14] [15] [16] [17] with for contraindication patellar malalignment. Then the medialization osteotomy originally described by Roux and subsequently modified and popularized by Elmslie and Trillat [18]. This surgical technique is recommended for patellar instability and lateral maltracking [18] [19]. Concerning the third technique of tibial tubercle osteotomy, it corresponds to the anteromedialization osteotomy or Fulkerson osteotomy originally described in 1983 and combining elements of both the Maquet and Elmslie-Trillat procedures which is indicated for patellofemoral pain failing non-operative interventions and patellar maltracking (including instability) or excessive tilt [13] [16] [20] [21] [22].

Overall, satisfactory outcomes have been reported for these procedures, with good to excellent results. For anteriorization osteotomy, the rate of excellent and good results after a short follow-up reported by Maquet in 1976, Sudman et al. in 1980, Ferguson et al. in 1982 and Svartveit et al. in 1983 varied from 85\% to $100 \%$ [15] [23] [24] [25]. However, two Scandinavian studies notably those of Lund et al. released in 1980 and that of Uppheim et al. published in 1982 with longer follow-up, showed a decreasing effect of the operation with time [26] [27]. Regarding the medialization osteotomy, Nakagawa et al. [28] reported 64\% of excellent to good outcomes on a series of 45 knees at an average follow-up of 161 months. On the anteromedialization osteotomy, the rate of excellent and good results ranged from $60 \%$ to $93 \%$ [13]. The original article by Fulkerson et al. found good subjective results for 28 of 30 patients [13]. The authors demonstrated a $93 \%$ rate of good to excellent outcomes. These findings were confirmed 
in a study of Bellemans et al. [21] who prospectively examined 29 patients with 97\% improvement in patellar congruence angle and subluxation, as well as improved functional outcomes. Buuck et al. [29] found at 4- to 12-year follow-up, that $86.4 \%$ of patients maintained good results.

In the literature, the failure rate of these procedures is estimated from $30 \%$ to $70 \%$ [3] [4]. This can be attributed to the different predisposing factors involved in the development of patellofemoral chondral disease and which are represented by: coronal and rotational malalignment of the lower limb (femur, tibia, rearfoot), muscular dysfunction (hip, thigh, core), patellofemoral dysplasia, patellar height, and gait impairment [1]. In this context, a few previous studies attempted to identify precisely the prognostic factors which influence the outcome of tibial tubercle osteotomy. Literature review highlights no correlation between the outcomes and sex, weight, duration of symptoms, preoperative pain score, and preoperative patellofemoral joint space narrowing. These findings also emerge in Jenny et al. [17] publication on 100 modified Maquet procedures and that of Wang et al. [4] in a study including 53 Fulkerson osteotomies. However, unsatisfactory results correlated for several authors with severe articular damage [4]. In the same frame, Pidoriano et al. [20] found that with distal and lateral patellar lesions had higher rates of satisfactory outcomes compared to patients with proximal or medial lesions, who tended to have poorer outcomes overall. Recently, many of the abovementioned variables were evaluated as potential prognostic factors. Rosso et al. [30] concluded in a correlation between poor outcomes and age higher than 45 years, increased femoral anteversion, foot pronation, positive postoperative crepitus, and postoperative muscular wasting.

For its high complication rate, especially skin necrosis, compartment syndrome and bone nonunion, the Maquet techniques were largely abandoned. The choice between medialization and anteromedialization osteotomy in the treatment of PFP remains a subject of debate. Ramappa et al. [31] examined the biomechanical effects of medial and anteromedial tibial tubercle transfer in $10 \mathrm{ca}-$ daveric specimens. Both procedures reduced contact stresses and corrected patellar maltracking in malaligned patellofemoral joints. However, the medialization of tibial tubercle has the merit of better correcting patellar tilt and redistributing contact forces from the lateral facet to the entire patella. Thus, medialization of the tibial tubercle can potentially further decrease the risk of lateral facet cartilage injury [31].

In our daily practice and taking into account its multiple technical and biomechanical advantages, the medialization osteotomy of tibial tubercle is our procedure of choice for treating patellofemoral instability on lateral maltracking with or without associated articular degeneration.

\section{Conclusion}

The Elmslie-Trillat procedure represents a simple, reliable and reproducible surgical technique for the management of patellofemoral pain in the context of pa- 
tellar instability and lateral maltracking in young and active patients who do not improve under physical therapy. With great conviction, we practice this procedure with a view to a large series and a possible extension of its indication to an older population.

\section{Conflicts of Interest}

The authors declare no conflicts of interest regarding the publication of this paper.

\section{References}

[1] Witvrouw, E., Callaghan, M.J., Stefanik, J.J., et al. (2014) Patellofemoral Pain: Consensus Statement from the 3rd International Patellofemoral Pain Research Retreat Held in Vancouver. British Journal of Sports Medicine, 48, 411-414.

https://doi.org/10.1136/bjsports-2014-093450

[2] McCarthy, M.M. and Strickland, S.M. (2013) Patellofemoral Pain: An Update on Diagnostic and Treatment Options. Current Reviews in Musculoskeletal Medicine, 6, 188-194. https://doi.org/10.1007/s12178-013-9159-x

[3] Carofino, B.C. and Fulkerson, J.P. (2008) Anteromedialization of the Tibial Tubercle for Patellofemoral Arthritis in Patients > 50 Years. Journal of Knee Surgery, 21, 101-105. https://doi.org/10.1055/s-0030-1247803

[4] Wang, C.J., Chan, Y.S., Chen, H.H. and Wu, S.T. (2005) Factors Affecting the Outcome of Distal Realignment for Patellofemoral Disorders of the Knee. Knee, 12, 195-200. https://doi.org/10.1016/j.knee.2004.08.006

[5] Lysholm, J., Gillquist, J. and Liljedahl, S.O. (1982) Long Term Results after Early Treatment of Knee Injuries. Acta Orthopaedica Scandinavica, 53, 109-118. https://doi.org/10.3109/17453678208992187

[6] Tegner, Y. and Lysholm, J. (1985) Rating Systems in the Evaluation of Knee Ligament Injuries. Clinical Orthopaedics and Related Research, No. 198, 43-49. https://doi.org/10.1097/00003086-198509000-00007

[7] Beighton, P. and Horan, F. (1969) Orthopaedic Aspects of the Ehlers-Danlos Syndrome. The Journal of Bone and Joint Surgery. British Volume, 51, 444-453. https://doi.org/10.1302/0301-620X.51B3.444

[8] Staheli, L.T., Corbett, M., Wyss, C. and King, H. (1985) Lower-Extremity Rotational Problems in Children: Normal Values to Guide Management. The Journal of Bone and Joint Surgery. American Volume, 67, 39-47. https://doi.org/10.2106/00004623-198567010-00006

[9] Aglietti, P., Insall, J.N. and Cerulli, G. (1983) Patellar Pain and Incongruence, I: Measurements of Incongruence. Clinical Orthopaedics and Related Research, 176, 217-224. https://doi.org/10.1097/00003086-198306000-00032

[10] Insall, J. and Salvati, E. (1971) Patella Position in the Normal Knee Joint. Radiology, 101, 101-104. https://doi.org/10.1148/101.1.101

[11] Shabshin, N., Schweitzer, M.E., Morrison, W.B. and Parker, L. (2004) MRI Criteria for Patella Alta and Baja. Skeletal Radiology, 33, 445-450. https://doi.org/10.1007/s00256-004-0794-6

[12] Wiberg, G. (1941) Roentgenographic and Anatomic Studies on the Femoropatellar Joint. Acta Orthopaedica Scandinavica, 12, 319-410.

https://doi.org/10.3109/17453674108988818 
[13] Fulkerson, J.P., Becker, G.J., Meaney, J.A., Miranda, M. and Folcik, M.A. (1990) Anteromedial Tibial Tubercle Transfer without Bone Graft. American Journal of Sports Medicine, 18, 490-496. https://doi.org/10.1177/036354659001800508

[14] Maquet, P. (1963) A Biomechanical Treatment of Femoro-Patellar Arthrosis: Advancement of the Patellar Tendon. Revue du Rhumatisme et des Maladies Osteo-Articulaires, 30, 779-783.

[15] Maquet, P. (1976) Advancement of the Tibial Tuberosity. Clinical Orthopaedics and Related Research, 115, 225-230. https://doi.org/10.1097/00003086-197603000-00039

[16] Ferguson, A.B., Brown, T.D., Fu, F.H. and Rutkowski, R. (1979) Relief of Patellofemoral Contact Stress by Anterior Displacement of the Tibial Tubercle. The Journal of Bone and Joint Surgery. American Volume, 61, 159-166. https://doi.org/10.2106/00004623-197961020-00001

[17] Jenny, J.Y., Sader, Z., Henry, A., Jenny, G. and Jaeger, J.H. (1996) Elevation of the Tibial Tubercle for Patellofemoral Pain Syndrome. An 8- to 15-Year Follow-Up. Knee Surgery, Sports Traumatology, Arthroscopy, 4, 92-96. https://doi.org/10.1007/BF01477260

[18] Trillat, A., Dejour, H. and Couette, A. (1964) Diagnosis and Treatment of Recurrent Dislocations of the Patella. Revue de Chirurgie Orthopedique et Reparatrice de Pappareil Moteur, 50, 813-824.

[19] Cox, J.S. (1982) Evaluation of the Roux-Elmslie-Trillat Procedure for Knee Extensor Realignment. American Journal of Sports Medicine, 10, 303-310. https://doi.org/10.1177/036354658201000509

[20] Pidoriano, A.J., Weinstein, R.N., Buuck, D.A. and Fulkerson, J.P. (1997) Correlation of Patellar Articular Lesions with Results from Anteromedial Tibial Tubercle Transfer. American Journal of Sports Medicine, 25, 533-537. https://doi.org/10.1177/036354659702500417

[21] Bellemans, J., Cauwenberghs, F., Witvrouw, E., Brys, P. and Victor, J. (1997) Anteromedial Tibial Tubercle Transfer in Patients with Chronic Anterior Knee Pain and a Subluxation-Type Patellar Malalignment. The American Journal of Sports Medicine, 25, 375-381. https://doi.org/10.1177/036354659702500318

[22] Fulkerson, J.P. (2002) Diagnosis and Treatment of Patients with Patellofemoral Pain. American Journal of Sports Medicine, 30, 447-456. https://doi.org/10.1177/03635465020300032501

[23] Sudmann, E. and Salkowitsch, B. (1980) Anterior Displacement of the Tibial Tuberosity in the Treatment of Chondromalacia Patellae. Acta Orthopaedica Scandinavica, 51, 171-174. https://doi.org/10.3109/17453678008990782

[24] Ferguson, A.B. (1982) Elevation of the Insertion of the Patellar Ligament for Patellofemoral Pain. Journal of Bone and Joint Surgery, 64, 766-771. https://doi.org/10.2106/00004623-198264050-00017

[25] Svartveit, K., Lilleby, H. and Roaas, A. (1983) Behandling av chondromalacia patellae ved ventralisering av tuberositas tibiae. Tidsskr Nor Lageforen, 103, 923-924.

[26] Lund, F. and Nilsson, B.E. (1980) Anterior Displacement of the Tibial Tuberosity in Chondromalacia Patellae. Acta Orthopaedica Scandinavica, 51, 679-688. https://doi.org/10.3109/17453678008990861

[27] Uppheim, G., Sorensen, R., Langhrd, O., Bakken, M., Korsell, E. and Langeland, N. (1984) Treatment of Chodromalacia Patellae. A Prospective Study. Acta Orthopaedica Scandinavica, 55, 694.

[28] Nakagawa, K., Wada, Y., Minamide, M., Tsuchiya, A. and Moriya, H. (2002) Dete- 
rioration of Long-Term Clinical Results after the Elmslie-Trillat Procedure for Dislocation of the Patella. The Journal of Bone and Joint Surgery. British Volume, 84, 861-864. https://doi.org/10.1302/0301-620X.84B6.0840861

[29] Buuck, D.A. and Fulkerson, J.P. (2000) Anteromedialization of the Tibial Tubercle: A 4- to 12-Year Follow-Up. Operative Techniques in Sports Medicine, 8, 131-137. https://doi.org/10.1053/otsm.2000.6581

[30] Rosso, F., Rossi, R., Governale, G., Marmotti, A., Cherubini, V., Cottino, U. and Bonasia, D.E. (2017) Tibial Tuberosity Anteromedialization for Patellofemoral Chondral Disease: Prognostic Factors. American Journal of Sports Medicine, 45, 1589-1598. https://doi.org/10.1177/0363546517690387

[31] Ramappa, A.J., Apreleva, M., Harrold, F.R., Fitzgibbons, P.G., Wilson, D.R. and Gill, T.J. (2006) The Effects of Medialization and Anteromedialization of the Tibial Tubercle on Patellofemoral Mechanics and Kinematics. American Journal of Sports Medicine, 34, 749-756. https://doi.org/10.1177/0363546505283460 